\title{
Morphological Studies on Epididymis and Vas Deferens of One - Humped Camel Bull (Camelus dromedarius), Uda Ram and Red Sokoto Buck
}

\author{
Muhammad Abdullahi Mahmud", , Josephat Onu², Sani Abdullahi Shehu², Aminu Umaru, \\ Abubakar Danmaigoro ${ }^{2}$, Mohammed Shaibu Atabo ${ }^{4}$ \\ ${ }^{1}$ Department of Animal Health and Production Technology, Niger State College of Agriculture, Mokwa, Niger State, Nigeria \\ ${ }^{2}$ Department of Veterinary Anatomy, Usmanu Danfodiyo University, Sokoto, Nigeria \\ ${ }^{3}$ Department of Theriogenology and Animal Production, Usmanu Danfodiyo University, Sokoto, Nigeria \\ ${ }^{4}$ Department of Animal Health and Production Technology, College of Agriculture and Animal Science, Bakura, Zamfara State, Nigeria
}

Email address:

drmahmud2@gmail.com (M. A. Mahmud)

\section{To cite this article:}

Muhammad Abdullahi Mahmud, Josephat Onu, Sani Abdullahi Shehu, Aminu Umaru, Abubakar Danmaigoro, Mohammed Shaibu Atabo. Morphological Studies on Epididymis and Vas Deferens of One - Humped Camel Bull (Camelus dromedarius), Uda Ram and Red Sokoto Buck. American Journal of Bioscience and Bioengineering. Vol. 3, No. 5, 2015, pp. 65-71. doi: 10.11648/j.bio.20150305.17

\begin{abstract}
This study was aimed at comparing morphology of the epididymis and vas deferens of One - humped Camel bull (OCB), Uda ram (UR) and Red Sokoto buck (RSB). Fifteen testes and vas deferens were collected, organs grossly examined, measured for weight or length and processed for histology. In OCB, epididymal tail was the largest of the three segments while a reverse of that was obtained in UR and RSB In OCB, the vas deferens was found to be coiled all through while in both UR and RSB, it was found to be highly coiled initially but became straightened as it coursed down to form ampulla. Gross morphometrically, the weight and length of epididymis and vas deferens in the three species differed significantly $(\mathrm{P}<0.05)$ from one another. Histomorphologically, in the corpus epididymis, stereocilia were prominently observed in UR followed by RSB and least in OCB. The proximal segment of vas deferens in the three species was found to consist of three histological layers; tunica mucosa from which, many folds extended, tunica muscularis and tunica serosa. Histomorphometrically, all measured parameters in both corpus epididymis and proximal segment of vas deferens in the three species differed significantly from one another. It was concluded that although results show that the studied animals are different ruminant species they exhibits some similarities and interesting morphological differences in epididymis and vas deferens compared to the majority of mammals. The basic morphological characterizations done in this study are important for future studies, such as comparison with other species of ruminants (whether true or pseudo).
\end{abstract}

Keywords: Morphology, Epididymis, Vas Deferens, Gross, Morphometry, Histomorphology, Histomorphometry

\section{Introduction}

The importance of epididymis and vas deferens in sperm production, storage and maturation and sperm transport respectively in domestic animals cannot be overemphasized, since survival of a species largely depends on its ability to reproduce its own kind [1]. This might be the reason why they received more attention especially the epididymis than any other segments of the excurrent duct of the testes. Recent studies on mammalian epididymis include those by $[1,2,3$, $4,5,6,7,8]$. Vas deferens on the other hand had received very little attention recently especially in one - humped camel, sheep and goat $[9,10]$. The epididymis is a highly convoluted tubule which connects the testis to the ductus deferens and is an important segment of the excurrent duct system of the testes that performs a variety of functions [11]. Various studies on mammalian epididymis have shown that it can be divided into distinct regions according to the biochemical, morphological and morphometric characteristics of its segments [12]. Various divisions have been proposed and the most widely used is that dividing the organ into the initial segment, caput, corpus and cauda epididymis [13]. The vas deferens is the tubular structure which conducts spermatozoa from the epididymis to the urethra. After crossing the ureter in the abdominal cavity it 
dilates into a spindle shaped enlargement, the ampulla [9]. Comparative anatomical and histological studies on epididymis and vas deferens of local domestic ruminants are not available, except few references that are available in the textbook on ruminants in general $[14,15]$. Therefore, this work highlights comparatively; gross anatomy, gross morphometry, histomorphology and histomorphometry of epididymis and vas deferens in one - humped Camel Bull, Uda ram and Red Sokoto buck.

\section{Materials and Methods}

Fifteen testes and vas deferens of apparently healthy adult one - humped Camel bulls, Uda rams and Red Sokoto bucks (five samples per species) were collected from Sokoto metropolitan abattoir. Sokoto metropolis is located on latitudes $10^{\circ} \mathrm{N}$ and $14^{\circ} 50^{\prime} \mathrm{N}$ and longitudes $7^{\circ} \mathrm{E}$, east of the equator, in the extreme northwest of Nigeria. It covers an area of approximately 2, 823, 237 square kilometres. The last National census reported the state population to be 3, 696, 999 [16]. Following the collection, they were transported to Veterinary Anatomy Laboratory, Usmanu Danfodiyo Sokoto, Nigeria where gross features of the epididymidis and vas deferens were examined and recorded. The epididymis was dissected out from the testes. The weights ( $\mathrm{g}$ ) and lengths (cm) were measured using a weighing balance (Shimadzu AW320, Germany), metre rule and thread respectively. Photographs were taken using digital camera (Samsung ES95, 16.2 megapixels). The sample tissues for histology in epididymis were obtained from the body (corpus) while that of vas deferens was taken from the proximal region (between the vaginal ring and ampulla). They were immediately fixed inside $10 \%$ neutral buffered formalin, labelled and kept for two days, followed by preservation in $70 \%$ ethyl alcohol. They were dehydrated through ascending grades of ethanol $(70 \%, 95 \%$ and absolute ethanol), cleared in xylene and embedded in paraffin wax. Serial sections of $5 \mu \mathrm{m}$ were cut and stained with Haematoxylin and Eosin (H \&E) [17]. Micrographs were conducted with a Light microscope connected to a video based, computer - linked system (Tuscen CMOS Camera: IS500, Resolution: 5.0 megapixels) at x400 magnifiation. Histormorphometry was equally done using the same programme software. The following measurements were performed in epididymis: epithelial height (excluding the stereocilia), tubular and luminal diameters and stereocilia height. In the vas deferens, the following measurements were done: thickness of tunica mucosa, thickness of tunica muscularis, thickness of tunica serosa and luminal diameter. The analysis was performed at x100 magnification with a scale bar of $100 \mu \mathrm{m}$, for both corpus epididymis and proximal vas deferens segments. The epididymal measurements were carried out according to the procedure of [12]. Briefly, the epithelial height was taken as the linear length of the principal cells, from the base of the epithelium (basal lamina) to the apical edge (excluding the stereocilia), the luminal diameter as the longest measurement from one apical edge to the other, and the tubular diameter as the longest distance between basal - basal laminas

Data analysis: Epididymis and vas deferens data obtained were expressed as Mean \pm SEM (Standard Error of Mean) and subjected to statistical analysis using Statistical Package for the Social Sciences (SPSS) version 17.0. One - Way Analysis Of Variance (ANOVA) at 95\% confidence interval (CI) was used to determine level of significant difference in mean values of the data. Values of $(\mathrm{P} \leq 0.05)$ were considered significant. Where there were differences in means, they were separated by Tukey's Honestly Significant Difference (HSD).

\section{Results}

\subsection{Gross Morphology}

\subsubsection{Epididymis}

The epididymides of the three species are shown on Plates $1,2 \& 3$. The epididymis was observed in the three species to be an elongated and convoluted tube that lies firmly attached laterally to the testis. The convoluted tube covers the superior pole of the testis and connects by a narrow corpus epididymis to cauda epididymis projecting from the distal border of the testis. In all the three studied species, the epididymis was macroscopically divided into three main segments; caput (head), corpus (body) and cauda (tail). In the one - humped camel bull, the tail was found to be the largest of the three segments, with the head curving on the cranial pole of the testes. The entire epididymis was loosely attached to the testes, with a soft consistency. In the Uda ram the epididymal head was found to be the largest of the three segments with the head markedly outlined and pointed dorsocranially with a faint neck outline. The terminal portion of the body was found not be attached to the testes and the tail was found to be attached in a caudodorsal direction. In the Red Sokoto buck, the general characteristic described above for the Uda was observed except that the head had a distinct neck with a smaller testicular bursa around the terminal portion of the body. The colour of epididymis was yellowish in both Uda rams and Red Sokoto buck though more in the buck, while that of the one - humped camel bull was greyish white.

\subsubsection{Vas Deferens}

The vas deferens of the three species is shown on Plates 1 , $2 \& 3$. The vas deferens was observed in the three species to be a continuation of the caudal epididymis which was more straightened, more tubular and more muscular than the epididymis. It extends from the tail of the epididymis to the pelvic urethra. In the one - humped camel bull, the vas deferens was found to be coiled all through but more before it became enlarged at its terminal portion to forms an ampulla, ventral to the prostate. In both Uda ram and Red Sokoto buck, the vas deferens was found to be highly coiled initially but became straightened as it coursed down to form ampulla. The vas deferens was observed to be longest in one - humped Camel bull, followed by that of the Uda ram and least in the Red Sokoto buck. 

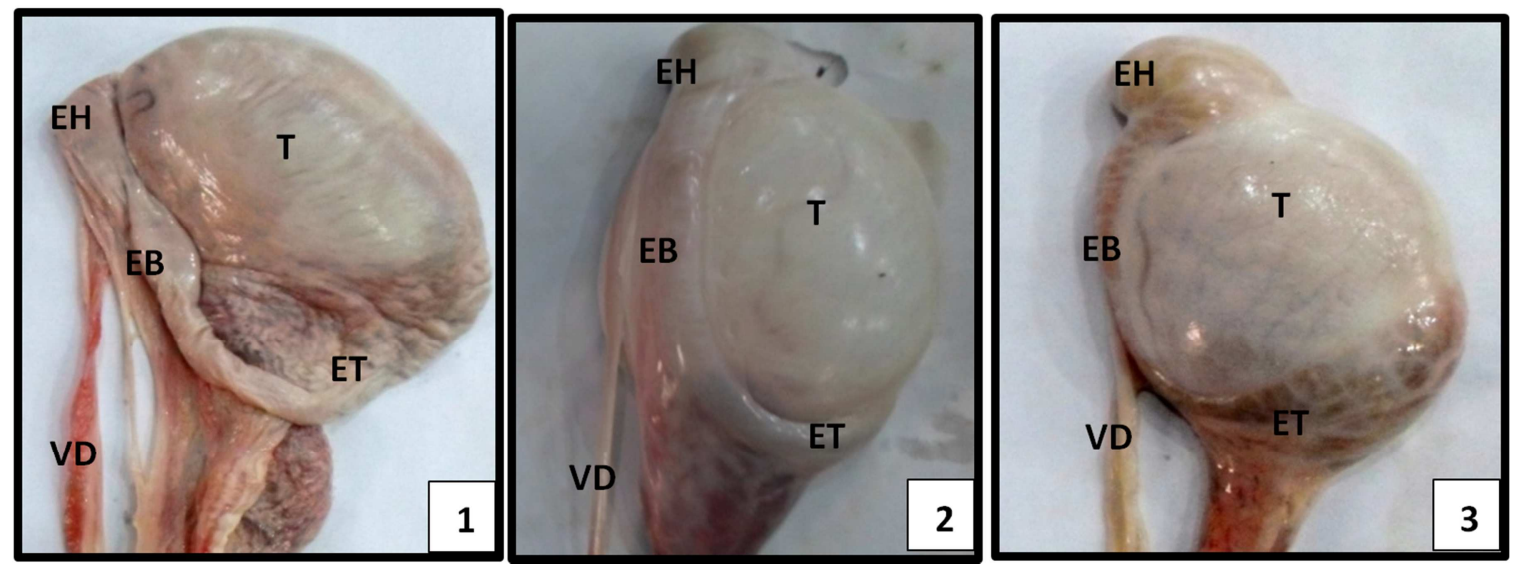

Plates 1, 2 and 3. Photograph of testes of OCB. 2. Photograph of testes of UR. 3. Photograph of testes of RSB, showing testes (T), epididymal head (EH), epididymal body (HB), epididymal tail (ET) and vas deferens (VD).

\subsection{Gross Morphometry}

Means \pm SEM of weights and lengths of epididymis and vas deferens of One - humped Camel bull (OCB), Uda ram (UR) and Red Sokoto buck (RSB) are shown in Table 1.

\subsubsection{Epididymis}

The results of the mean epididymal length of OCB, UR and RSB indicated that the means differed significantly $(p \leq 0.05)$ in the three species. The mean epididymal length of $19.00 \pm 1.72 \mathrm{~cm}$ in UR differed significantly $(\mathrm{p} \leq 0.05)$ from those of OCB $(14.88 \pm 1.33 \mathrm{~cm})$ and RSB $(13.06 \pm 0.35 \mathrm{~cm})$.

The results of the mean epididymal weight of OCB, UR and RSB indicated that the means differed significantly $(\mathrm{p} \leq 0.05)$. The mean epididymal weight of $46.55 \pm 1.28 \mathrm{~g}$ in OCB was significantly $(\mathrm{p} \leq 0.05)$, the highest in the three species, followed by that of UR $(24.21 \pm 3.67 \mathrm{~g})$ and least in $\operatorname{RSB}(7.18 \pm 0.35 \mathrm{~g}) \cdot 3.2 .2$ Vas deferens

The results of the mean vas deference length of OCB, UR and RSB indicated that the means differed significantly $(\mathrm{p} \leq 0.05)$. The mean vas deferens length of $35.67 \pm 1.23 \mathrm{~cm}$ in OCB was significantly $(\mathrm{p} \leq 0.05)$, the highest in three species, followed by that of UR $(29.81 \pm 0.76 \mathrm{~cm})$ and least in RSB
$(15.00 \pm 0.53 \mathrm{~cm})$.

Table 1. Mean \pm SEM of weights (g) and lengths $(\mathrm{cm})$ of different parts of Reproductive Tracts of the one - hump camel bull (OCB), the Uda ram (UR) and Red Sokoto buck (RSB).

\begin{tabular}{llll}
\hline Parameters & OCB & UR & RSB \\
\hline EL & $14.88 \pm 1.33 \mathrm{~b}$ & $19.00 \pm 1.72 \mathrm{a}$ & $13.06 \pm 0.35 \mathrm{~b}$ \\
EW & $46.55 \pm 1.28 \mathrm{a}$ & $24.21 \pm 3.67 \mathrm{~b}$ & $7.18 \pm 0.35 \mathrm{c}$ \\
VDL & $35.67 \pm 1.23 \mathrm{a}$ & $29.81 \pm 0.76 \mathrm{~b}$ & $15.00 \pm 0.53 \mathrm{c}$ \\
\hline
\end{tabular}

a, b, c Means within the same row without the same superscript letters are significantly different $(p \leq 0.05)$ from each other. $\mathrm{EL}=$ Epididymal length, $\mathrm{EW}=$ Epididymal weight, $\mathrm{VDL}=$ Vas deferens length.

\subsection{Histomorphology}

\subsubsection{Corpus Epididymis}

The mucosae of the corpus epididymis were found to comprise pseudostratified columnar epithelium with stereocilia, basal cells at the lamina propria, muscularis, vascular connective tissue as well as spermatozoa in the lumen. The stereocilia were found to be more extensive in UR than in the RSB and least prominent in the OCB (Plates $4,5$ and 6$)$.
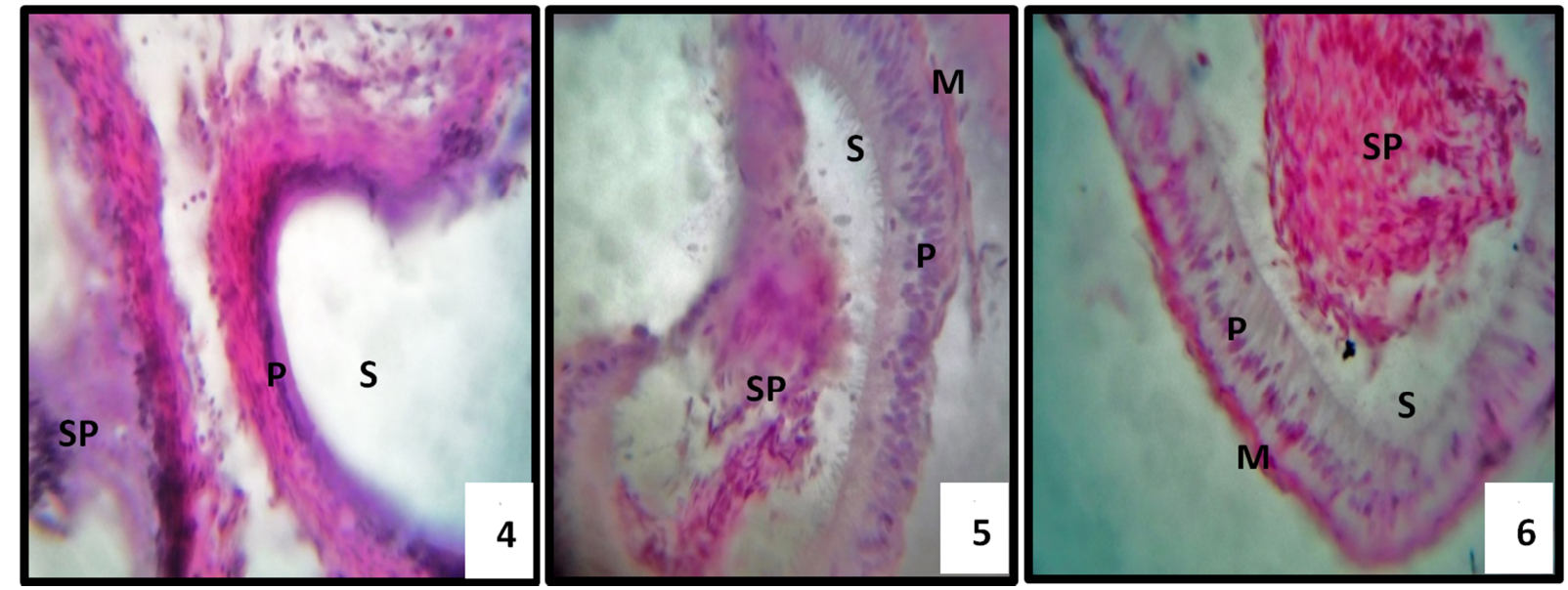

Plates 4, 5 and 6. Micrographs of epididymis (transverse sections) of OCB, UR and RSB, showing the mucosa lined by pseudostratified columnar epithelium $(P)$ with stereocilia $(S)$, muscularis $(M)$, and presence of spermatozoa $(S P)$ in the epididymal lumen $(H \& E x 400$, Scale bar $=100 \mu m)$. 


\subsubsection{Proximal Vas Deferens}

The vas deferens was observed to be thick with mucosal folds, resulting in irregular outline of the lumen. Also observed were thick layers of smooth muscle of muscularis externa and serosa. The mucosa was observed to be thickest in OCB and least in RSB. The number of mucosal folds was observed to be highest in UR and least in OCB (Plate 7, 8 and 9).
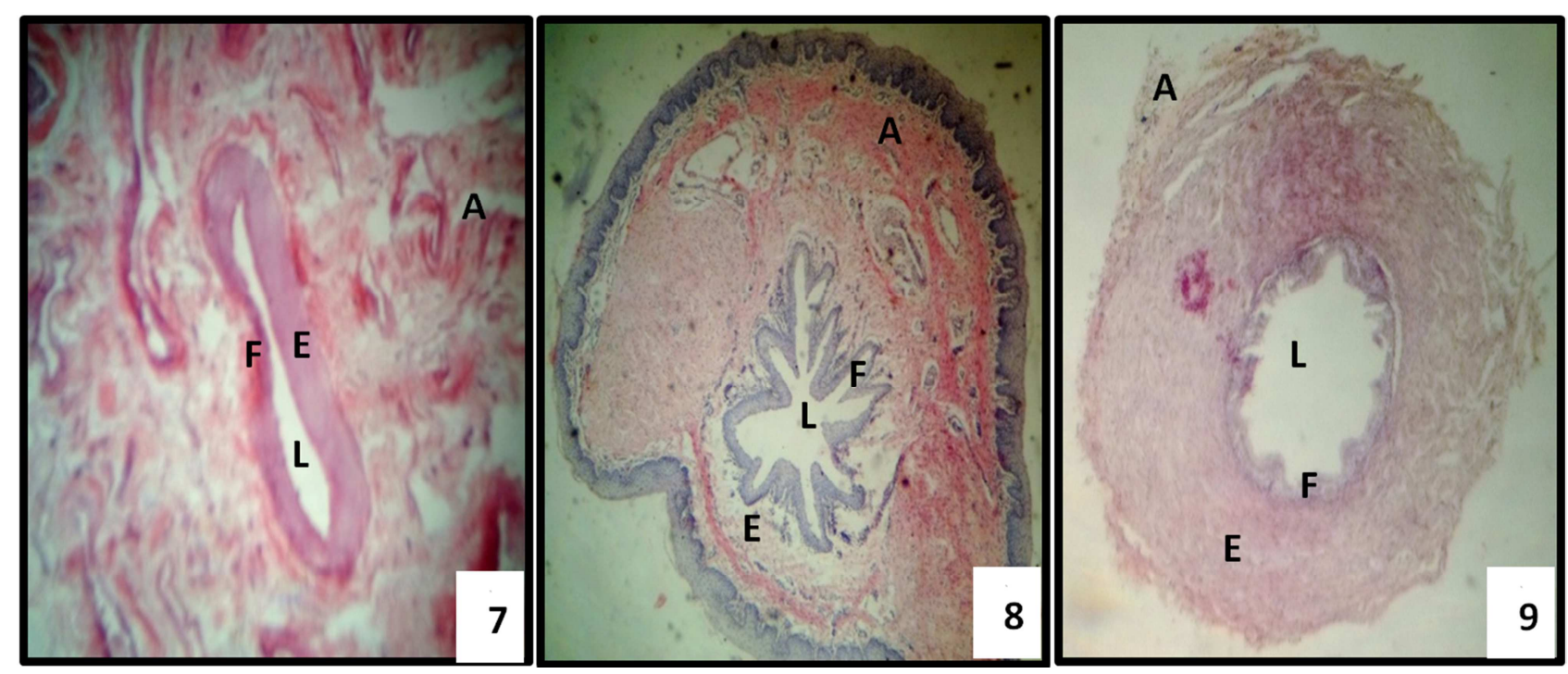

Plates 7, 8 and 9. Micrographs of vas deferens (transverse section) of OCB (7), UR (8) and RSB (9), showing lumen (L), mucosal folds (F), thick layer of smooth muscle of muscularis externa (E) and adventitia $(A)(H \& E x 40$, Scale bar $=100 \mu \mathrm{m})$.

\subsection{Histo - Morphometry}

The various histomorphometric dimensions of the corpus epididymis and the proximal vas deferens in the three studied species are shown in Figs. 1and 2 respectively.

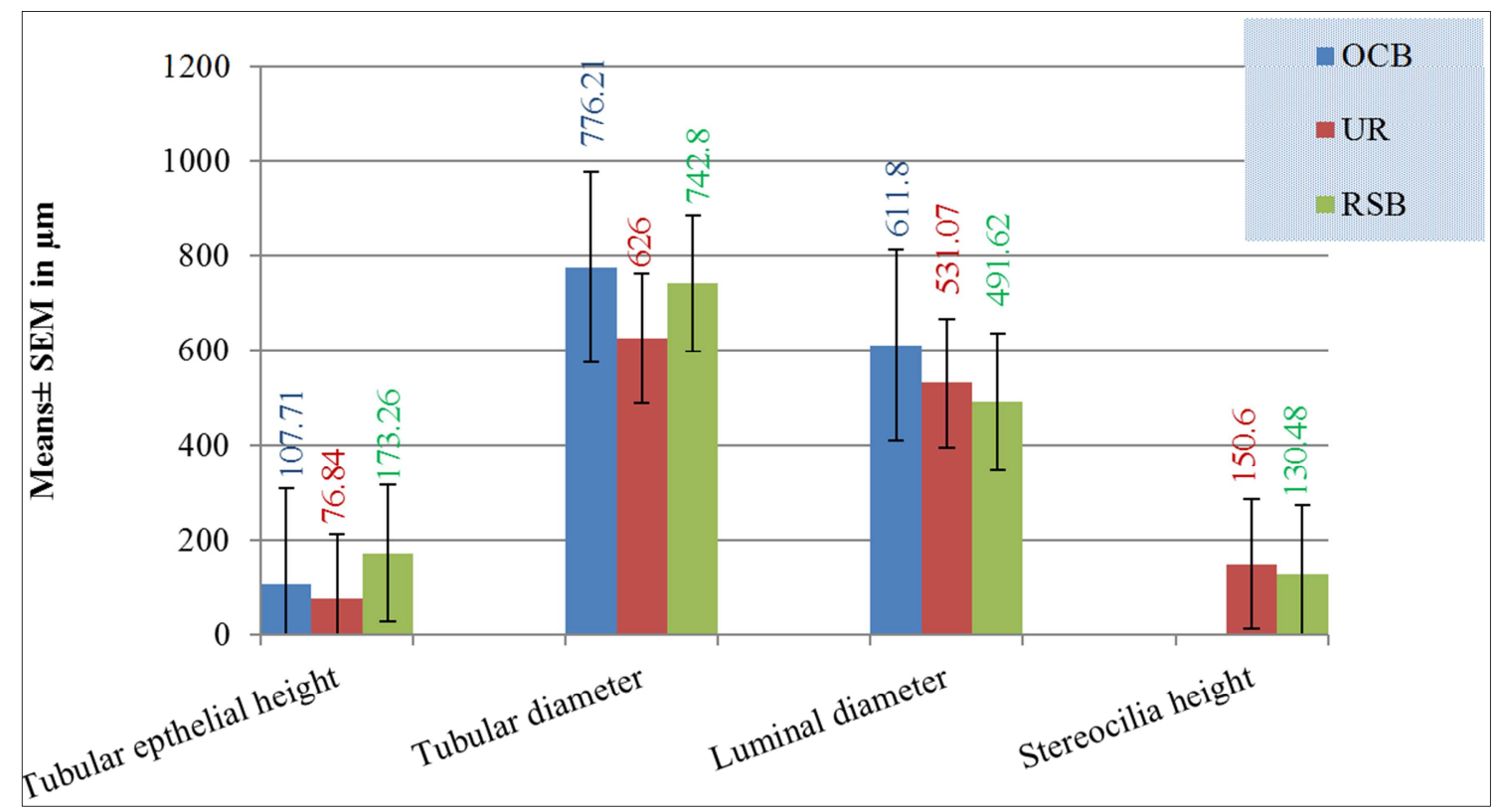

Fig. 1. Histormorphometric parameters of Corpus Epididymis.

\subsubsection{Corpus Epididymis}

The mean epithelial height of RSB $(173.26 \pm 19.46 \mu \mathrm{m})$ significantly differed $(\mathrm{p} \leq 0.05)$ from those of UR $(76.84 \pm$ $3.28 \mu \mathrm{m})$ and $\mathrm{OCB}(107.71 \pm 7.06 \mu \mathrm{m})$.
The mean tubular diameters of $776.21 \pm 23.03 \mu \mathrm{m}$ in OCB and $742.80 \pm 21.97 \mu \mathrm{m}$ in RSB significantly differed $(\mathrm{p} \leq 0.05)$ from a mean value of $626.00 \pm 30.42 \mu \mathrm{m}$ recorded in UR.

The mean luminal diameters of $611.80 \pm 32.25 \mu \mathrm{m}$ and $491.62 \pm 34.95 \mu \mathrm{m}$ in OCB and RSB respectively significantly 
differed $(\mathrm{p} \leq 0.05)$ from each other while that of UR (531.07 \pm $29.82 \mu \mathrm{m})$ did not differ $(\mathrm{p}>0.05)$ from any of them.

The stereocilia heights of $150.61 \pm 14.53 \mu \mathrm{m}$ and $130.48 \pm$ $15.45 \mu \mathrm{m}$ in UR and RSB respectively did not differ significantly $(p>0.05)$ from each other. However, it is numerically higher in UR than RSB.

\subsubsection{Proximal Vas Deferens}

The sizes (thickness) of tunica mucosa and tunica muscularis of proximal vas deferens in the three species were found to be significantly different $(p \leq 0.05)$ from one another. RSB was found to have the thickest $t$. mucosa and $t$. muscularis with mean values of $257.74 \pm 30.88 \mu \mathrm{m}$ and $1202.29 \pm 49.31 \mu \mathrm{m}$ respectively. This was followed by UR with mean values of $180.60 \pm 27.29 \mu \mathrm{m}$ and $755.25 \pm 70.85$ $\mu \mathrm{m}$ respectively. The least values of $92.47 \pm 11.29 \mu \mathrm{m}$ and $560.74 \pm 51.60 \mu \mathrm{m}$ respectively were recorded for OCB.

The mean thickness values of the $t$. serosa of $245.88 \pm$ $17.90 \mu \mathrm{m}$ and $401.87 \pm 60.45 \mu \mathrm{m}$ in UR and RSB respectively were found to be significantly $(\mathrm{p} \leq 0.05)$ different from that of OCB $(1561.41 \pm 92.07 \mu \mathrm{m})$.

The mean values for vas deferens luminal diameter though not significantly $(p>0.05)$ different in the three species, numerically, the OCB had highest mean value of $1567.77 \pm$ $534.37 \mu \mathrm{m}$, followed by UR with a mean value of $1327.79 \pm$ $241.90 \mu \mathrm{m}$ and least in RSB with a mean value of $1209.36 \pm$ $37.55 \mu \mathrm{m}$.

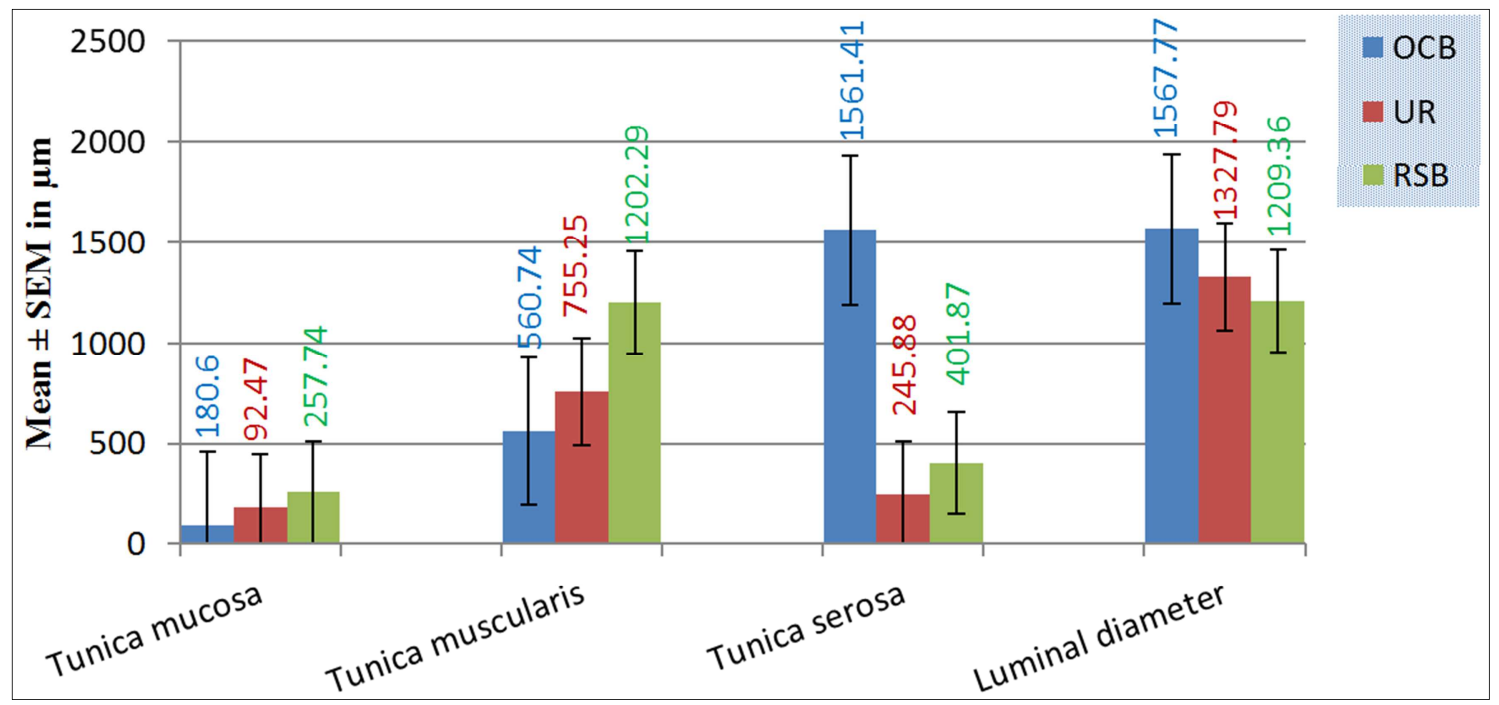

Fig. 2. Histomorphometric parameters of Vas Deferens.

\section{Discussion}

The macroscopic division of the epididymis in the three species into three segments; the head (caput), the body (corpus) and the tail (cauda), follows general pattern as earlier described by [18] in mammals, [19] in one - humped camel and [14] in small ruminants. In this present study, the OCB epididymal tail which was found to be the largest of the three segments agrees with the reports of [19] in OCB. The result however, is contrary to the earlier reports of [20], who reported that the body of the epididymis of one - humped camel accounts for almost $50 \%$ of the total epididymal weight. It is also not in agreement with the reports of [21] and [22] in bulls and bucks respectively, who reported that the caput is the largest of the three segments.

The result of this study on the vas deferens of OCB found to be coiled all through, but more before it became enlarged at its terminal portion where it formed ampulla, agrees with the reports of [23] who said, the vas deferens in one humped camel is coiled initially. He further said its distinct ampullary enlargement is present in the terminal $4.0-5.0 \mathrm{~cm}$ which enters the urethra ventral to the corpus prostate. The present finding is however, contrary to the reports of [24], who reported that, the vas deferens in one - humped camel is remarkably twisted for much of its initial course, but becomes fairly straight towards the end portion.

The mean epididymal weight $(24.21 \pm 3.67 \mathrm{~g})$ of the UR obtained in this study is close to the mean value of $25.5 \pm$ $0.28 \mathrm{~g}$ earlier reported by [25] in Nigerian Uda ram but higher than mean weights of $134.48 \pm 2.28 \mathrm{~g}$ and $19.12 \pm$ $0.12 \mathrm{~g}$ respectively reported by [26] for West African dwarf ram. This difference may be attributed to genotype, as the West African dwarf ram had been described as the smallest breed of indigenous sheep in Nigeria [27].

The mean length of vas deferens of $35.67 \pm 1.23 \mathrm{~cm}$ found in this study for OCB is below the range of $45-50 \mathrm{~cm}$ reported by [19] in one - humped camels. The mean vas deference in RSB of $15.00 \pm 0.53$ found in this report is contrary to the earlier reports by [9] of $29.86 \pm 1.38 \mathrm{~cm}, 31.71$ $\pm 0.84 \mathrm{~cm}$ and $40.18 \pm 1.59 \mathrm{~cm}$ in pre - pubertal, pubertal and post pubertal Gaddi goats respectively.

The findings on least prominence of stereocilia observed in the corpus epididymis of OCB agree with earlier reports of [28] in one - humped camel. [29] have mentioned that, in one - humped camel, the proximal part of the middle epididymis possesses high epithelium with long stereocilia, the intermediate part is characterized by the cytoplasmic vacuoles, mass collections of spermatozoa in the lumen and 
short stereocilia. Whereas the distal part of the middle epididymis, is the longest of all the segments and extended over most of what is classically described as the corpus epididymidis. It is characterized by low epithelium; the lumen is very wide packed with spermatozoa and shortest stereocilia. This could mean that there might be less absorptive and secretory functions of the tubular epithelium of the corpus epididymis in OCB compared to the corpus epididymides of the other two species.

The results on histomorphometry could not be adequately compared to the findings of other workers due to paucity of available relevant literature. However, some histomorphometric results obtained in this study are of much higher values than what where earlier observed in Malabari goats [30], Black Bengal bucks [31] and camel [29]. The different results may be due to sampling from different positions, different magnification or different calibrations.

\section{Conclusions}

The results show that although the studied animals are different species of ruminant they exhibits some similarities and interesting morphological differences in epididymis and vas deferens compared to the majority of mammals. The basic morphological characterizations done in this study are important for future studies, such as comparison with other species of ruminants (whether true or pseudo).

\section{References}

[1] Sharma RK, Goyal AK and Veena Y (2014): Histological Studies on Epididymis Region of Goat (Capra Hircus) Reproductive System. International Journal of Pure and Applied Zoology 2 (3): 224 - 227.

[2] Crichton EG and Krutzsch PH (2000): Reproductive biology of bats. Academic Press, London, United Kingdom. 528 p.

[3] Shimming BC and Vicentini CA (2001): Ultrastructural features in the epididymis of the dog (Canis familiaris, L). Anatomia, Histologia Embryologia 30: 327 - 332.

[4] Shimming BC, Vicentini CA, Tirapelli LF and Tirapelli DPC (2002): Morphological examination of the epididymal duct in the dog. Brazilian Journal of Veterinarian Research and Animal Science 39 (2): 61 - 65.

[5] Aguilera - Merlo C, Muñoz E, Dominguez S, Scardapane L and Piezzi R (2005): Epididymis of viscacha (Lagostomus maximus maximus): Morphological changes during the annual reproductive cycle. Anatomical Record 282: 83 - 92.

[6] Domeniconi RF, Orsi AM, Beu CCL and Felisbino SL (2007): Morphological features of the epididymal epithelium of gerbil, Meriones unguiculatus. Tissue and Cell 39: 47 - 57.

[7] Awobajo FO, Raji Y and Akinloye A K (2010): Histomorphometric Changes in the Testes and Epididymis of Wistar Strain Albino Rats Following Fourteen Days Oral Administration of Therapeutic Doses of Some Antibiotics. International Journal of Morphology 28 (4): 1281 - 1287.

[8] Sharma K, Kalita SN, Sarma M and Devi J (2011): Postnatal development of the caput epididymis in Assam goat (Capra hircus). Indian Journal of Animal Sciences 81 (9): 932-934.

[9] Archana P, Katiyar RS, Sharma DN and Farooqui MM (2008): Age associated changes in the histochemistry of vas deferens in Gaddi goat (Capra hircus). Indian Journal of Animal Sciences 78 (7): 714-717.

[10] Ubaid AK, Kazim DA, Hussain, HN and Ubaid JK (2012): Histological Study of Proximal Segment for Vas Deferens in the indigenous Mature goats. Scientific Journal of University of Karbala 10 (1): 85 - 90 .

[11] Beu CC, Orsi AM and Domeniconi RF (2009): Structure of the lining epithelium of the cauda epididymis of the golden hamster. Anatomia, Histologia and Embryologia 38 (1): 49 - 57.

[12] Beguelini1 MR, Bruno FS, Sergio, Fábio LJ, Leme, Sebastião R, Taboga, Morielle - Versute E (2010): Morphological and morphometric characteristics of the epididymis in the Neotropical bats Eumops glaucinus and Molossus molossus (Chiroptera: Molossidae). Chiroptera Neotropical 16 (2): 769 -779 .

[13] Serre V and Robaire B (1998): Segment - specific morphological changes in aging brown Norway rat epididymis. Biology of Reproduction 58: 497 - 513.

[14] Dyce KM, Sack WO and Wensing CJG (2002): Textbook of Veterinary Anatomy. (3rd edition). W. B. Saunders Company, USA. Pp: 188 - 190.

[15] Sisson S and Grossman JD (1975): The Anatomy of Domestic Animal. (4th edition). W.B. Saunders Company, USA. Pp: $701-710$.

[16] NPC (2006): National Population Commission, Nigeria.

[17] Drury RAB and Wallington EA (1976): Carleton's Histological Techniques. (4th edition). Oxford University Press, London. Pp. 21 - 71.

[18] Nickel R, Schummer A and Seiferle E (1979): The Viscera of the Domestic Mammals. (2nd Edition). Verlag Paul Parey Berlin, Hamburg. Pp: $120-130$.

[19] Skidmore L (2000): Anatomy of the camel reproductive tract. Recent advances in camelid reproduction. International Veterinary Information Service, Ithaca, New York, USA.

[20] Osman A and el - Azab E (1974): Gonadal and Epididymal Sperm Reserves in the Camel (Camelus dromedaries). Journal of Reproduction and Fertility 38: 452 - 430.

[21] Bitto II and Okpale MI (2006): Sperm production rate, Gonadal and extragonadal sperms reserves in slaughtered White Fulani (Bunaji) bulls in a lowland tropical environment. Nigerian Journal of Animal Production 33 (2): 300 - 3007.

[22] Ugwu SOC (2009): Relationship between Scrotal circumferences, in situ Testicular Measurement and Sperm Reserves in the West African Dwarf Bucks. African Journal of Biotechnology 8 (7): 1354 - 7 .

[23] Degen AA, Lee DG (1982): The male genital tract of the dromedary (one humped) Camelus dromedarius. Gross and microscopic anatomy. Anatomia, Histologia and Embryologia 11: $267-82$.

[24] Mukasa - mugerwa E (1981): The camel (Camelus dromedarius), a bibliographical review. International Livestock Centre for Africa, Addis Ababa, Mimeo. P: 147. 
[25] Abdullahi AI, Aliyu J, Ashiru RM and Jamilu M (2012): Biometric Study on the Reproductive Organs of Three Breeds of Sheep in Nigeria. International Journal of Morphology, 30 (4): 1597 - 1603 .

[26] Ahemen T and Bitto II (2007): Sperm production rate, Gonadal and extragonadal sperm reserves of the West African Dwarf rams in Makurdi. March 18 - 21. Proceedings of the 32nd Annual Conference. Of Nigerian Society for Animal Production Vol. 1, Pp. 99 - 101.

[27] Osinowo OA (1990): Breed selection, reproduction and breed management in the local small ruminant breeds. In: The Nigerian sheep and goat production manual. Zaria, NAPRI Workshop Training (A.O. Osinowo andA.A. Abatan, editors). Pp: $7-18$.
[28] Glover T and Nicander L (1971): Some Aspects of Structure and Function in the Mammalian Epididymis. Journal of Reproduction and Fertility 13 (13): 39 - 50.

[29] Tingari M D and Moniem K A (1979): On the regional histology and histochemistry of the epididymis of the camel (Camelus dromedarius). Journal of Reproduction and Fertility 57: 11-20.

[30] Harshan K R, Radhakrishnan, K, Ommer P A and Paily L (1978): Postnatal development of epididymis of Malabari goat (Capra hircus). India Journal of Animals Health 9: 279-89.

[31] Pyne S K (1987): Studies on the histological structure of epididymis in normal and vesectomised goats (Capra hircus). Indian Journal Animal Health 26: 145-49. 